\title{
Cytokine pre-activation of cryopreserved xenogeneic-free human mesenchymal stromal cells enhances resolution and repair following ventilator-induced lung injury potentially via a KGF-dependent mechanism
}

Shahd Horie ${ }^{1,2}$, Sean Gaynard², Mary Murphy ${ }^{2,3}$, Frank Barry ${ }^{2,3}$, Michael Scully ${ }^{1,2}$, Daniel O'Toole ${ }^{1,2+}$ and John G. Laffey ${ }^{1,2,4^{*}+}$ (1)

* Correspondence: john.laffey@
nuigalway.ie
${ }^{+}$Daniel OToole and John G. Laffey
contributed equally to this work.
${ }^{1}$ Anaesthesia, School of Medicine,
National University of Ireland,
Galway, Ireland
${ }^{2}$ Regenerative Medicine Institute
(REMEDI) at CÚRAM Centre for
Research in Medical Devices,
National University of Ireland
Galway, Galway, Ireland
Full list of author information is
available at the end of the article

* Correspondence: john.laffey@ nuigalway.ie contributed equally to this work. ${ }^{1}$ Anaesthesia, School of Medicine, of Ireland (REMEDI) at CURAM Centre for Research in Medical Devices, National University of Ireland available at the end of the article

\author{
Abstract \\ Background: Human mesenchymal stem/stromal cells (hMSCs) represent a \\ promising therapeutic strategy for ventilator-induced lung injury (VILI) and acute \\ respiratory distress syndrome. Translational challenges include restoring hMSC \\ efficacy following cryopreservation, developing effective xenogeneic-free (XF) hMSCs \\ and establishing true therapeutic potential at a clinically relevant time point of \\ administration. We wished to determine whether cytokine pre-activation of \\ cryopreserved, bone marrow-derived XF-hMSCs would enhance their capacity to \\ facilitate injury resolution following VILI and elucidate mechanisms of action.
}

Methods: Initially, in vitro studies examined the potential for the secretome from cytokine pre-activated XF-hMSCs to attenuate pulmonary epithelial injury induced by cyclic mechanical stretch. Later, anaesthetised rats underwent VILI and, $6 \mathrm{~h}$ following injury, were randomized to receive $1 \times 10^{7} \mathrm{XF}-\mathrm{hMSC} / \mathrm{kg}$ that were (i) naive fresh, (ii) naive cryopreserved, (iii) cytokine pre-activated fresh or (iv) cytokine pre-activated cryopreserved, while control animals received ( $v$ ) vehicle. The extent of injury resolution was measured at $24 \mathrm{~h}$ after injury. Finally, the role of keratinocyte growth factor (KGF) in mediating the effect of pre-activated XF-hMSCs was determined in a pulmonary epithelial wound repair model.

Results: Pre-activation enhanced the capacity of the XF-hMSC secretome to decrease stretch-induced pulmonary epithelial inflammation and injury. Both preactivated fresh and cryopreserved XF-hMSCs enhanced resolution of injury following VILI, restoring oxygenation, improving lung compliance, reducing lung leak and improving resolution of lung structural injury. Finally, the secretome of pre-activated XF-hMSCs enhanced epithelial wound repair, in part via a KGF-dependent mechanism.

(Continued on next page) 
(Continued from previous page)

Conclusions: Cytokine pre-activation enhanced the capacity of cryopreserved, XFhMSCs to promote injury resolution following VILI, potentially via a KGF-dependent mechanism.

Keywords: Acute respiratory distress syndrome, Ventilation-induced lung injury, Injury resolution and repair, Mesenchymal stem/stromal cells, Cryopreservation, Cell

activation

\section{Background}

Mechanical ventilation is a potentially life-saving manoeuvre in patients with acute respiratory distress syndrome (ARDS) [1,2], but it can also exacerbate lung damage-this is termed ventilation-induced lung injury (VILI) [3]. Mesenchymal stem/stromal cells (MSCs) demonstrate beneficial effects in diverse pre-clinical lung injury models including pulmonary [4-6] and abdominal sepsis [7-9], bleomycin-induced acute lung injury [10] and fibrosis [11, 12]. Human-derived MSCs (hMSCs) enhance injury resolution following established VILI [13, 14], enhance recovery of human lungs ex vivo [15] and reduce the severity of Escherichia coli pneumonia [16]. Finally, recent phase 1-2 studies suggest that allogeneic bone marrow-derived hMSCs (BM-hMSCs) can be safely administered to patients with moderate to severe ARDS [17, 18].

In regard to clinical translation of hMSC therapies, concern exists that the cryopreservation and thawing processes may reduce the efficacy of hMSCs and its secretome [19]. The use of xenogeneic products, particularly foetal bovine serum (FBS)based media for passage of MSCs [20], has generated important safety concerns [21], including the risk of virus and prion contamination, and concerns regarding immunogenicity [22-25]. Xenogeneic culture-free (XF) supplements such as the recently patented XF supplement (WO2015121471 A1) have been developed that preserve the differentiation, proliferation and low immunogenicity properties of MSCs [26]. Finally, demonstrating true 'therapeutic' potential of MSC therapies, i.e. showing efficacy at later points (delayed administration) in the injury and/or repair process, is necessary to better mimic the clinical scenario.

Cytokine activation of hMSCs may enhance their function by simulating the inflammatory/injury microenvironment [27-29], potentially minimizing any impact of cryopreservation, XF culture conditions or loss of therapeutic efficacy with delayed delivery following disease onset. We wished to test the hypothesis that pre-activation of cryopreserved, XF-hMSCs would enhance their efficacy after delayed administration in a relevant preclinical model of VILI injury and repair and to investigate the mechanisms underlying these effects. In vitro studies examined the potential for naive and cytokine pre-activated XF-hMSC-conditioned medium (CM) to attenuate pulmonary epithelial stretch-induced injury. In vivo experiments examined the potential for cytokine preactivation to enhance the efficacy of (fresh and cryopreserved) XF-hMSCs to enhance resolution when administered at therapeutically relevant time points following the development of VILI. Subsequent mechanistic experiments examined the potential for the pulmonary epithelial reparative effects of XF-hMSCs to be mediated in part via KGF present in the MSC secretome. 


\section{Materials and methods \\ hMSC isolation, culture and expansion}

hMSCs were isolated from healthy donor bone marrow as previously described [30] and used at passages 2-3 for all experiments. MSCs were cultured in Alpha Minimum Essential Eagle Medium (MEM- $\alpha$ ) with GlutaMAX (GIBCO $\left.{ }^{\circ}\right)$ supplemented with $10 \%$ FBS, penicillin G (100 U/mL), streptomycin $(100 \mu \mathrm{g} / \mathrm{mL})$ and FGF-1 (10 ng/mL) (PeproTech EC Ltd., London, UK). hMSCs were maintained in 95\% humidity, 5\% $\mathrm{CO}_{2}$ and hypoxia $\left(2 \% \mathrm{O}_{2}\right)$ at $37^{\circ} \mathrm{C}$; sub-cultured with $0.025 \%$ trypsin- $0.05 \mathrm{mM}$ EDTA; and cryopreserved in CryoStor cell preservation medium (Sigma-Aldrich) at a density of $5 \times$ $10^{6} / \mathrm{mL}$. XF-hMSCs were isolated as above but expanded using an FBS-free medium containing a patented XF (WO2015121471 A1) growth supplement [26]. Following expansion, hMSCs were pre-activated with cytokine cocktail consisting of interleukin (IL) $-1 \beta$ (10 ng/mL), tumour necrosis factor (TNF)- $\alpha(50 \mathrm{ng} / \mathrm{mL})$ and interferon (IFN)- $\gamma$ $(50 \mathrm{ng} / \mathrm{mL})$ for $24 \mathrm{~h}$, and either delivered freshly harvested or cryopreserved and stored for later delivery. IL-8 secretion from naive or pre-activated hMSCs, before and after freezing (24 and $48 \mathrm{~h}$ post-cryopreservation), was determined using an IL- 8 sandwich ELISA DuoSet kit (R\&D Systems Inc., Minneapolis, MN, USA) to confirm the responsive state persisted post-thaw (Additional file 1: Figure S1). For in vivo experiments, cryopreserved XF-hMSCs were stored for up to 2 months and cell viability after thaw was between 95 and $97 \%$ as determined by trypan blue exclusion.

\section{hMSC-conditioned medium}

hMSCs were seeded at $1 \times 10^{4}$ cells $/ \mathrm{cm}^{2}$ in a $175-\mathrm{cm}^{2}$ culture flask and left to reach confluence for $48 \mathrm{~h}$. The cells were then re-fed with complete FBS medium or XF medium with or without cytokine cocktail for $24 \mathrm{~h}$. For naive CM, phosphate-buffered saline (PBS) vehicle was added for $24 \mathrm{~h}$. All cells were washed with PBS three times and re-fed with serum-free medium, to remove pre-activating cytokines. This CM was harvested $24 \mathrm{~h}$ later. Serum-free MEM- $\alpha$ medium was used for the control treatment groups in experiments. Multiple donors and multiple batches were used in all experiments.

\section{Pulmonary epithelial stretch injury model}

A549/NF-kB-luc cells were seeded to laminin-coated 6-well BioFlex plates (Flexcell International, Burlington, NC, USA) at $1 \times 10^{5}$ cells $/ \mathrm{cm}^{2}$ and incubated for $48 \mathrm{~h}$. They were then pre-conditioned in their respective hMSC CM treatment or control (MEM- $\alpha$ medium) conditions for $1 \mathrm{~h}$ before they were mounted onto the Flexcell FX-4000 $\mathrm{T}^{\oplus}$ Tension Plus ${ }^{\oplus}$ baseplate (Flexcell International) and subjected to $22 \%$ equibiaxial stretch at a frequency of $0.1 \mathrm{~Hz}$ for $120 \mathrm{~h}$. Non-stretched cells were used as control [31]. Cells and medium were then harvested for analysis. Cells were scraped into $1 \mathrm{~mL}$ of PBS, centrifuged at $400 \times g$ for $5 \mathrm{~min}$ and reconstituted in $1 \mathrm{~mL}$ of PBS. $50 \mu \mathrm{L}$ was taken for the viability assay and the remainder then pelleted again for the luciferase assay.

Injury assessment

IL-8, an NF-kB-dependent cytokine, was measured in the medium using an IL-8 sandwich ELISA DuoSet kit (R\&D Systems). Lactate dehydrogenase (LDH) was measured to 
assess cell membrane integrity using the CytoTox 96 Non-Radioactive Cytotoxicity Assay Kit (Promega Corporation, Fitchburg, WI, USA), as per the manufacturer's instructions. Cellular NF- $\mathrm{kB}$ activity was measured by mixing cell pellets with $50 \mu \mathrm{L}$ of SolarGlow SuperBright (Molecutools, Dublin, Ireland), agitating for 5 min and assessing luminescence using a VICTOR ${ }^{\mathrm{mm}} \mathrm{X}$ plate reader (Perkin Elmer, Waltham, MA, USA). An MTT (Sigma-Aldrich) assay was performed to assess cell viability as previously described [32].

\section{Ventilator-induced lung injury}

As previously described [33-35], rats were anaesthetised with isoflurane and intravenous access was obtained via the tail vein. Laryngoscopy was performed, and a 14-G catheter (BD Insyte ${ }^{\circ}$; Becton Dickinson Ltd., Oxford, UK) was used to intubate the animal for ventilation using a small animal ventilator (CWE SAR 830 AP; CWE Inc., Ardmore, PA, USA). Anaesthesia was maintained with repeated boli of Alfaxan ${ }^{\circ}$ (Alfaxadone $0.9 \%(\mathrm{w} / \mathrm{v})$ and alfadolone acetate $0.3 \%(\mathrm{w} / \mathrm{v})$; Vétoquinol S A, Lure Cedex, France) and paralysis with cisatracurium besylate $0.5 \mathrm{mg} . \mathrm{kg}^{-1}$ (GlaxoSmithKline, Dublin, Ireland). Following baseline ventilation, static compliance was measured and VILI was induced using the following ventilator settings: $\mathrm{Fi}_{\mathrm{O} 2}$ of $0.3, P_{\text {insp }} 35 \mathrm{cmH}_{2} \mathrm{O}$, respiratory rate $18 \mathrm{~min}^{-1}$ and PEEP $0 \mathrm{cmH}_{2} \mathrm{O}$. Following the development of severe VILI, as evidenced by a $50 \%$ decrease in respiratory static compliance, injurious ventilation was discontinued, and the animals allowed to recover from anaesthesia [34].

\section{Experimental design}

Six hours following cessation of injurious ventilation, animals were randomized to receive, by intravenous administration, either (i) vehicle ( $1 \mathrm{~mL}$ PBS) or $1 \times 10^{7} \mathrm{XF}$ $\mathrm{hMSCs} / \mathrm{kg}$ that were (ii) fresh naive hMSCs, (iii) cryopreserved naive hMSCs, (iv) fresh pre-activated hMSCs and (v) cryopreserved pre-activated hMSCs. The extent of inflammation and injury resolution was measured at $24 \mathrm{~h}$ (i.e. $18 \mathrm{~h}$ post-intervention delivery).

\section{In vivo assessment of lung injury and recovery}

Twenty-four hours post-cessation of injurious ventilation, animals were reanaesthetised as described above, intravenous access was obtained via tail vein and a tracheostomy tube was inserted [34]. Following the commencement of ventilation, intra-arterial access was gained and anaesthesia was maintained with $\mathrm{Saffan}^{\circ}$ and paralysis with cisatracurium besylate. Arterial blood pressure, airway pressure, lung static compliance and arterial blood gas analyses were performed as previously described [36, 37].

\section{Ex vivo analyses of lung inflammation and repair}

Following exsanguination under anaesthesia, bronchoalveolar lavage (BAL) was collected, and BAL fluid differential leukocyte counts were completed. BAL concentrations of CINC-1, IL-6, IL-10, KGF and $\mathrm{PGE}_{2}$ were determined using ELISA (R\&D Systems), and BAL protein was also measured (Micro BCA; Pierce, Rockford, IL, USA). The left lung was isolated and fixed, and structural lung damage determined using stereological 
techniques [38], a quantitative, robust and reproducible approach to histological assessment [39]. All ex vivo analyses were performed by blinded investigators.

\section{Pulmonary epithelial wound injury}

A549/NF-kB-luc cells were seeded at $1 \times 10^{5} \mathrm{cells} / \mathrm{cm}^{2}$ in a 24 -well plate (Sarstedt) and left to reach confluence for $48 \mathrm{~h}$. Single scratch wounds were generated with a $1-\mathrm{mL}$ pipette tip (Sarstedt). The cells were washed with PBS, and their respective treatments were added. Ten per cent serum was also added. Cell treatments were MEM- $\alpha$ medium, naive FBS- or XF-MSC CM, or pre-activated FBS- or XF- MSC CM +/-, a KGF neutralization antibody $(0.5 \mu \mathrm{g} / \mathrm{mL}$ ) (R\&D Systems). Wound restitution was assessed over $48 \mathrm{~h}$ using light microscopy imaging.

\section{Statistical analysis}

The distribution of all data was tested for normality using Kolmogorov-Smirnov tests. Data was analysed by one-way or repeated measures ANOVA, with post hoc StudentNewman-Keuls for between-group comparisons, and is presented as mean \pm standard deviation. A two-tailed $P$ value of $<0.05$ was considered statistically significant.

\section{Results}

In vitro assessments

\section{Pulmonary epithelial cell stretch-induced injury}

Cyclic mechanical stretch-induced NF- $\mathrm{kB}$ activation was attenuated by both FBS- and XF-cultured hMSC-CM as compared to the control (MEM- $\alpha$ ) group (Fig. 1a). Cytokine pre-activation of both FBS- and XF-cultured MSCs enhanced the efficacy of hMSC-CM in attenuating NF- $\mathrm{kB}$ activation. Cyclic mechanical stretch-induced IL-8 release was attenuated by FBS- and XF-cultured MSC-CM (Fig. 1b). Cytokine pre-activation of XFcultured-but not FBS-cultured-MSCs enhanced the efficacy of hMSC-CM in attenuating stretch-induced IL-8 release. Cyclic mechanical stretch caused pulmonary epithelial cell membrane injury, as evidenced by LDH release (Fig. 1c). This pulmonary epithelial injury was attenuated by hMSC-CM from both FBS- and XF-cultured MSCs. Cytokine pre-activation of FBS-cultured-but not XF-cultured-MSCs enhanced the efficacy of hMSC-CM in attenuating epithelial injury (Fig. 1c). Cyclic mechanical stretch decreased pulmonary epithelial cell viability, and this decrement in cell viability was abrogated by hMSC-CM from both FBS- and XF-cultured MSCs (Fig. 1d). Pre-activation of XF-cultured-but not FBS-cultured-MSCs further enhanced the efficacy of its CM in maintaining epithelial cell viability.

Injury resolution following in vivo ventilation-induced ARDS

Recovery of lung function

VILI resulted in a significant decrement in oxygenation and lung compliance and a significant increase in lung permeability compared to protective ventilation (Fig. 2). Both fresh and cryopreserved XF-hMSCs restored arterial oxygenation (Fig. 2a) when compared to the vehicle (PBS) control group. Cytokine pre-activation of cryopreservedbut not fresh-XF-hMSCs further enhanced restoration of arterial oxygenation (Fig. 2a). Cytokine pre-activated-but not naive-fresh and cryopreserved XF-hMSCs restored 


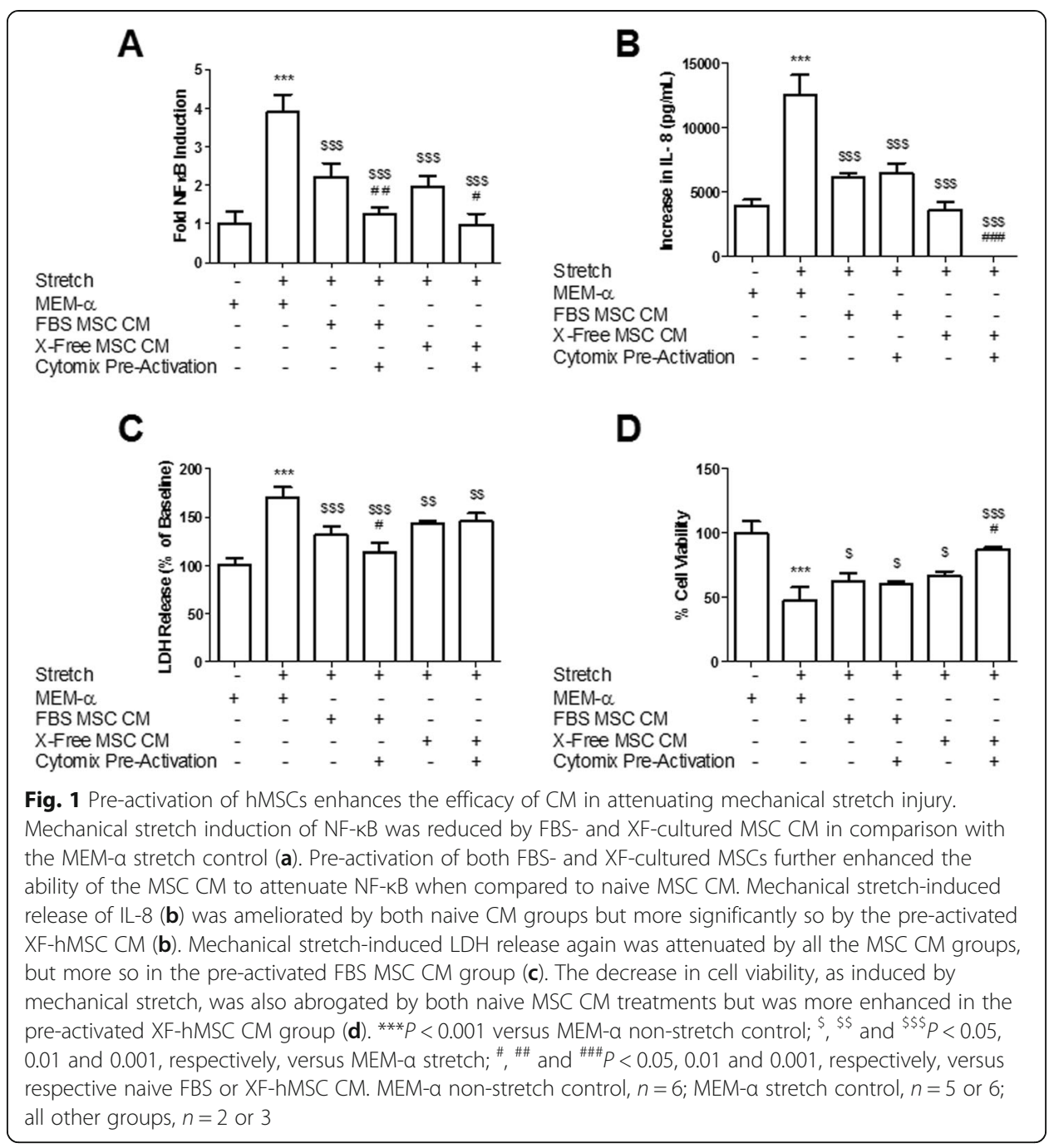

lung compliance (Fig. 2b). Both naive and cytokine pre-activated fresh and cryopreserved XF-hMSCs enhanced resolution of lung oedema (Fig. 2c). Cytokine preactivated-but not naive-fresh and cryopreserved XF-hMSCs restored alveolar barrier permeability, as evidenced by decreased BAL protein concentrations (Fig. 2d).

\section{Modulation of the inflammatory response}

Fresh, but not cryopreserved, XF-hMSCs decreased alveolar infiltrating cell counts, while cytokine pre-activation restored the efficacy of cryopreserved hMSCs in reducing alveolar cell counts (Additional file 2: Figure S2). Both fresh and cryopreserved XF-hMSCs decreased alveolar neutrophil counts (Fig. 3a). These effects were not significantly enhanced by cytokine pre-activation of either fresh or cryopreserved hMSCs (Fig. 3a). Fresh and cryopreserved hMSCs-whether naive or pre-activated-significantly attenuated the increase in alveolar CINC-1 (Fig. 3b) and IL-6 (Fig. 3c) concentrations. Pre-activated, but not naive, fresh XFhMSCs significantly increased alveolar concentrations of anti-inflammatory IL-10 (Fig. 3d), pro-repair KGF (Fig. 3e) and immunomodulatory $\mathrm{PGE}_{2}$ (Fig. 3f). Cryopreserved XF-hMSCs, both naive and pre-activated, did not modulate IL-10, KGF or $\mathrm{PGE}_{2}$ concentrations (Fig. 3). 


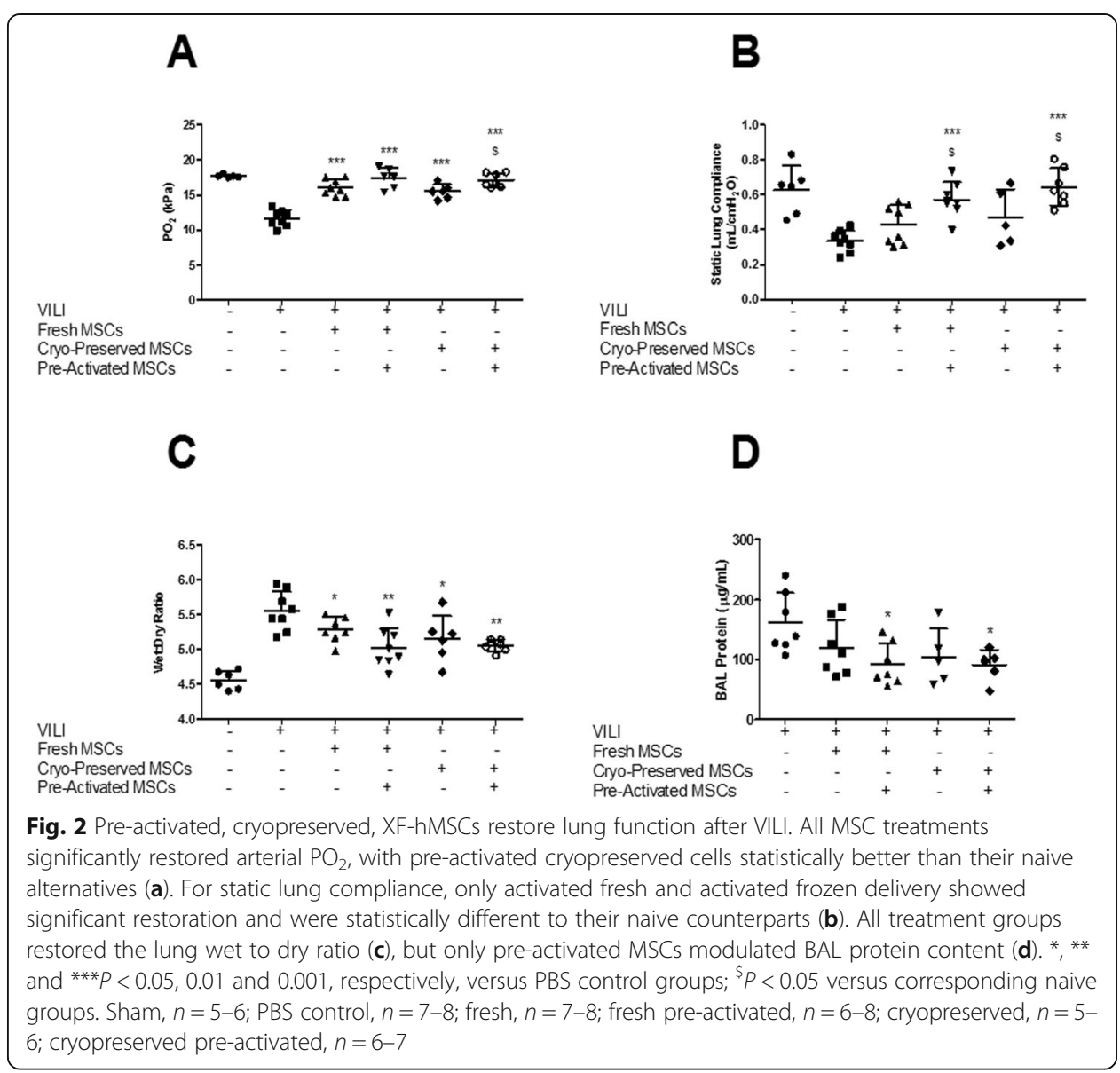

\section{Restoration of lung structure}

Treatment with fresh or cryopreserved hMSCs-both naive or pre-activated-fully restored lung histologic structure post-VILI as assessed by percentage airspace (Fig. 4a) and the resolution of interstitial and alveolar inflammatory infiltrates (Fig. 4b).

\section{Mechanisms of action-hMSC secretome Epithelial wound healing}

hMSC CM, whether from FBS- or XF-cultured cells, significantly improved pulmonary epithelial wound repair, an effect which was further enhanced with cytokine preactivation (Fig. 5a). The effect of cytokine pre-activation was blocked by the addition of a KGF-neutralizing antibody (Fig. 5b, c).

\section{Discussion}

In this paper, we present several important findings, each of translational significance. First, we demonstrate that the efficacy of MSCs was preserved when cultured in the xenogeneic material-free medium compared to the standard medium containing xenogeneic (bovine) products, an important advance. Second, we demonstrate that MSCs subjected to cryopreservation and thawing maintained efficacy compared to fresh MSCs in a relevant preclinical model of VILI. Third, we demonstrate the potential for 


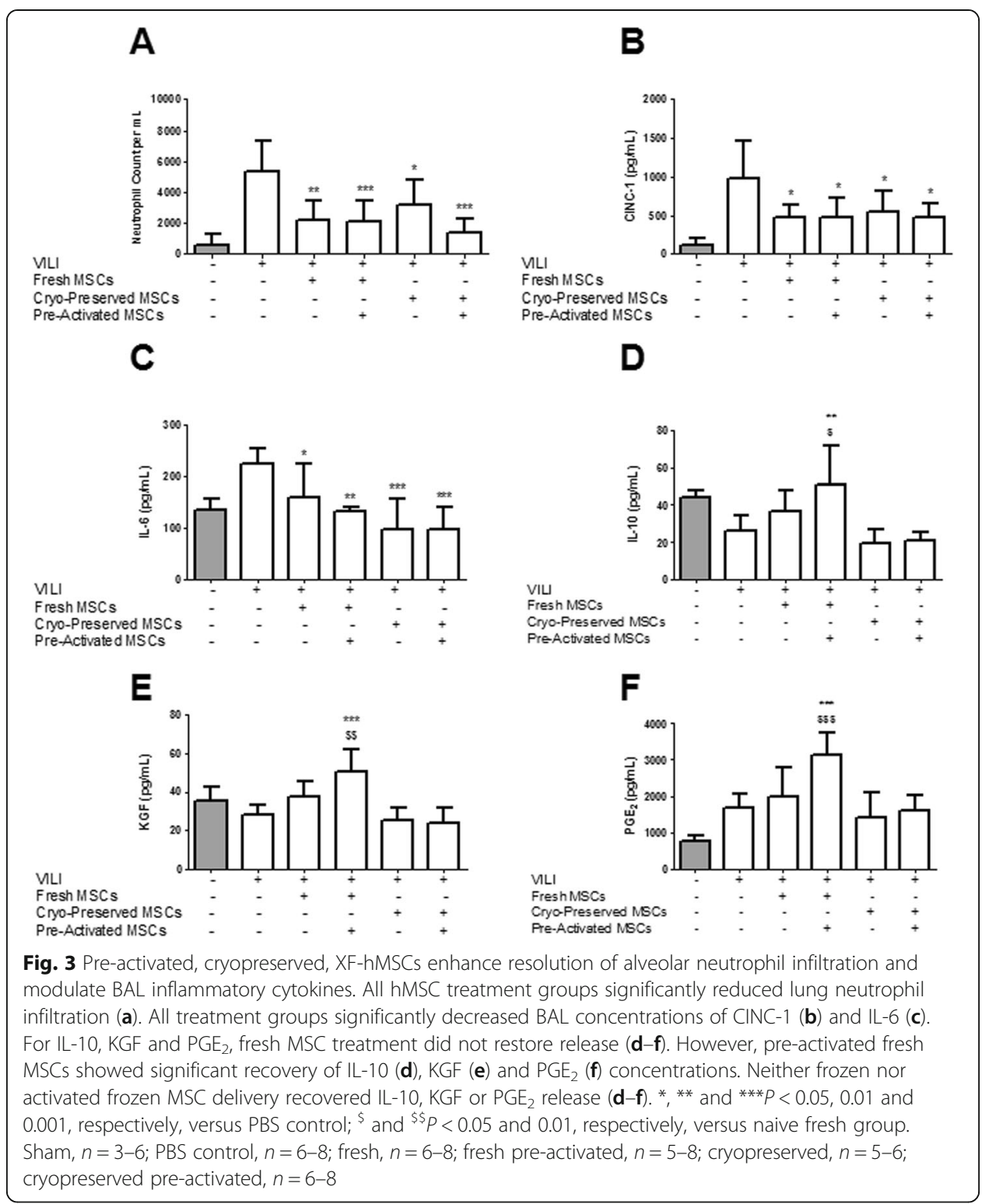

cytokine pre-activation to enhance the efficacy of MSCs and specifically their potential to enhance the efficacy of cryopreserved xeno-free MSCs. Fourth, we illustrate the potential role of KGF in mediating some of the protective effects of these cryopreserved xeno-free MSCs in a relevant pulmonary epithelial repair model. Taken together, these findings address important translational concerns and significantly advances these cells towards clinical testing for patients with ARDS.

\section{Cryopreservation of hMSCs}

Cryopreservation and storage of hMSCs would enable banking of hMSC batches that could then be thawed and administered in a timely fashion to patients with acute conditions such as ARDS. The alternative, namely provision of freshly cultured hMSC, would require that hMSCs are continuously available for harvest, in facilities adjacent 


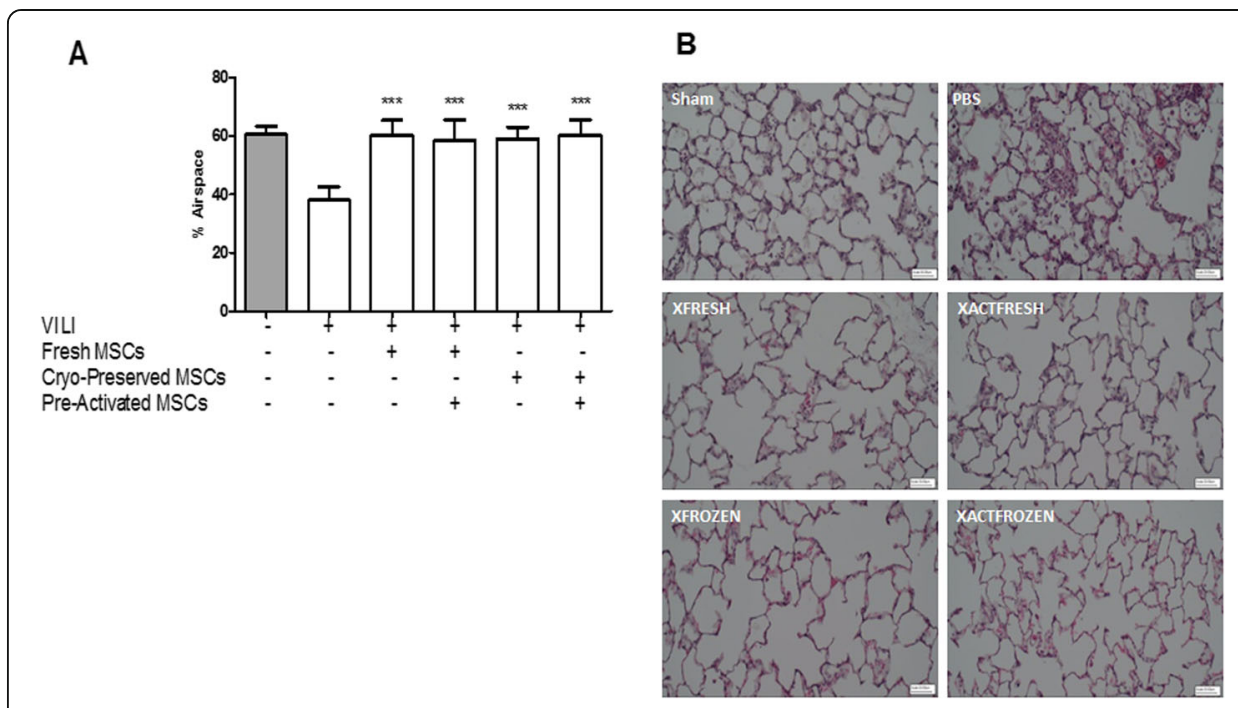

Fig. 4 Pre-activated, cryopreserved, XF-hMSCs restore lung structure. All cell treatment groups significantly restored the percentage of alveolar airspace in VILI (a). Representative images of lung histology sections are provided (b). ${ }^{* *} P<0.001$ versus PBS control group. Sham, $n=4$; PBS control, $n=8$; fresh, $n=8$; fresh preactivated, $n=7$; cryopreserved, $n=6$; cryopreserved pre-activated, $n=7$

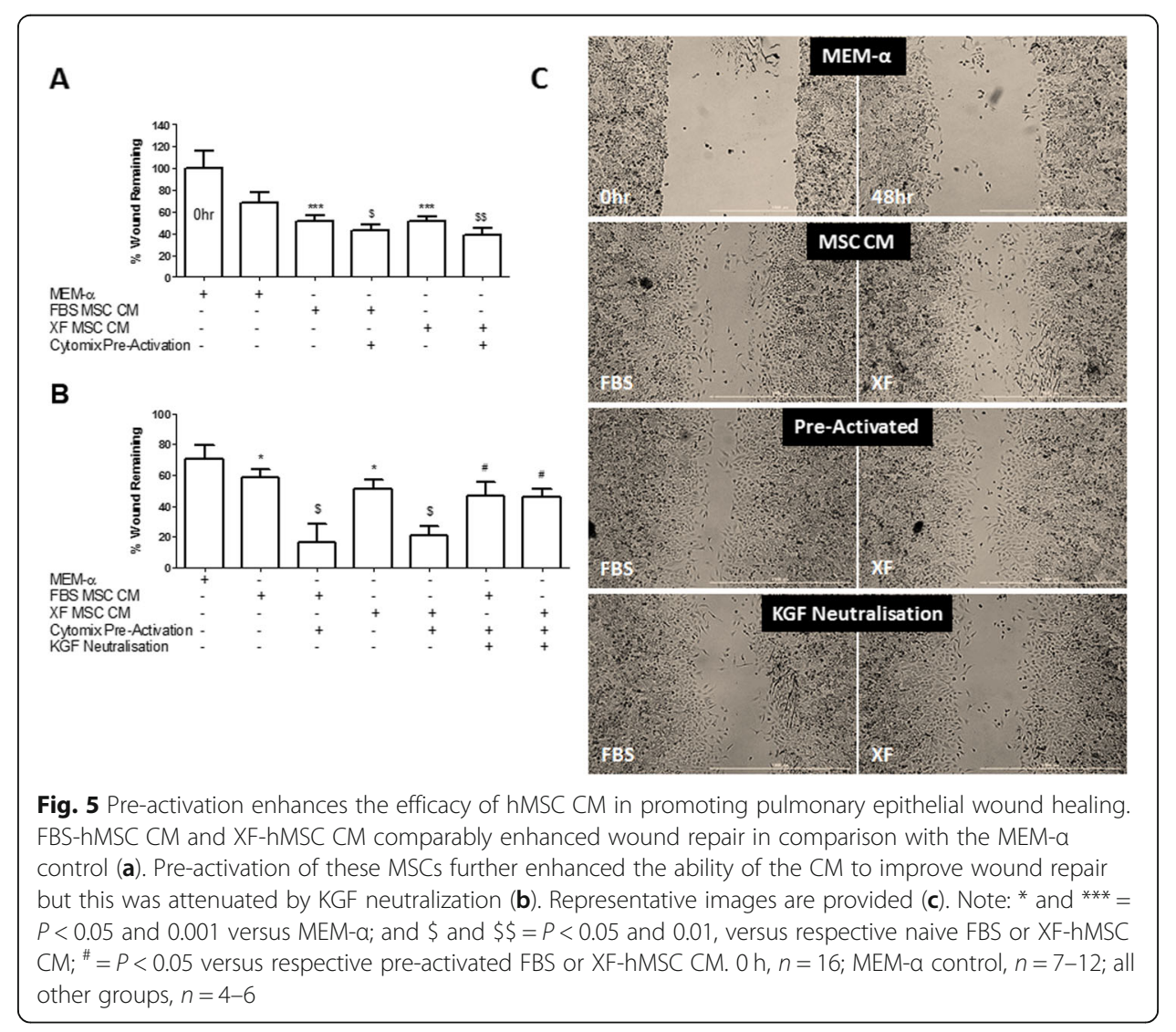


to the clinical settings, which presents substantial logistical and economic challenges. Other challenges include the risk of increased cell batch variability and the potential for contamination of batches. However, several studies demonstrate that the cryopreservation and thawing processes may significantly reduce the efficacy of hMSCs [19, 40]. Our finding that cryopreserved XF-hMSCs can enhance the resolution of VILI when administered at therapeutically relevant time points in our rodent model supports recent findings in other models, including pneumonia-induced ARDS [41], and are important demonstrations of the feasibility of cryopreservation of hMSCs. This insight is further supported by the observation that the secretory profile of hMSCs in regard to IL-8 release, whether the hMSCs were pre-activated or not, remained the same pre- and post-cryopreservation.

\section{Xenogeneic-free hMSCs}

Conventional culture and passage of MSCs requires the use of xenogeneic supplements to aid cell growth and replication, which includes the use of FBS that contains large amounts of growth factors [42]. However, the risks posed by the use of animal products in the culture medium of hMSCs intended ultimately for use in humans have been highlighted by the European Medicines Agency and US Food and Drug Administration [21]. Concerns include the risk of contamination or immunogenicity [22-25]. XF culture supplements would resolve these concerns. It has proven challenging to identify alternatives to FBS that maintain comparable growth conditions for MSCs and that do not adversely alter cell efficacy [42]. The recently patented XF supplement (WO2015121471 A1) has been demonstrated to preserve the differentiation, proliferation and low immunogenicity properties of MSCs [26]. Our finding that hMSCs cultured in this XF supplement retain the capacity to enhance the resolution of injury in our preclinical model of rodent VILI and maintain the secretome efficacy in attenuating pulmonary epithelial injury induced by cyclic stretch, and promoting wound healing in vitro, are important demonstrations of the therapeutic potential of XF-cultured hMSCs.

\section{hMSC secretome}

MSCs release soluble anti-inflammatory and pro-repair molecules [43-45], a mechanism of action that has raised interest in the use of the MSC secretome as an alternative to MSC cell therapy. This study demonstrated that the secretome of XF-hMSCs protected the pulmonary alveolar epithelium from injurious cyclic stretch and also demonstrates that pre-activation with inflammatory cytokines enhanced secretome efficacy (Additional file 1: Figure S1 and Additional file 2: Figure S2). These findings were also true for the enhancement of wound healing. We further went on to show that KGF neutralization can negate the enhancement observed as a result of cytokine preactivation. These outcomes extend findings from previous in vitro and in vivo studies showing that the MSC secretome resolved the inflammatory response and promoted repair and recovery post-VILI $[13,33]$ and thus strengthens the justification for the use of the secretome as a viable alternative therapy against VILI. However, it should be noted that the secretome may be less effective compared to hMSCs, especially in the early phases of the injury resolution process [46]. 


\section{Activation of hMSCs}

MSCs are responsive to their microenvironment [44, 47] potentially providing a means of enhancing their efficacy via pre-activation strategies prior to their delivery. Recent studies have shown that MSCs pre-activated with inflammatory cytokines possess enhanced therapeutic properties [48]. Several other promising MSC activation strategies have been elucidated, including IL-10 overexpression [49] and interferon- $\gamma$ priming [50]. Our studies advance our understanding of the therapeutic potential of priming by demonstrating that cytokine pre-activation can restore and/or enhance the function of cryopreserved XF-cultured hMSCs.

One aim in pre-activating cryopreserved MSCs with cytomix was to restore any therapeutic potency that might have been lost during cryopreservation. In regard to oxygenation, where cryopreserved MSCs only partially restored oxygenation, preactivation did further enhance restoration of oxygenation. The second aim was to enhance MSC capacity to restore function post-VILI. In regard to lung compliance, where the effect of even fresh MSCs was limited, pre-activation enhanced both the cryopreserved and the fresh MSCs in restoring lung compliance.

Importantly, cytokine activation prior to cryopreservation enhanced the hMSC efficacy following storage and subsequent thawing and administration to the animals following VILI at a later and more clinically relevant time point. This provides an important finding with regard to other pre-activation or enhancement strategies for hMSC therapy applications, and it suggests such modifications are compatible with cryopreservation protocols.

\section{Limitations}

There are a number of limitations to these studies. First, while we provide data to demonstrate that pre-activation of cryopreserved XF hMSCs enhances their ability to promote injury resolution following VILI and the ability of their secretome to reduce stretch injury and promote pulmonary epithelial wound repair, these studies were carried out in a rodent model and in vitro, and caution must be exercised in extrapolating to the clinical situation. However, we have used a clinically relevant injury resolution VILI model and utilized human MSCs. Thus, these findings strongly suggest that the therapeutic potential of cryopreserved XF-hMSCs for human ARDS may be enhanced by pre-activation measures. Second, we did not use a control non-stem cell group, such as a fibroblast group. In our previous experiments, rodent fibroblasts had no beneficial effect [35], while in experiments using human fibroblasts in rodents, some parameters indicative of injury were worsened [51]. Therefore, we believe that a fibroblast control is not justifiable for these studies. Our in vitro studies used A549 cells, an adenocarcinoma human alveolar basal cell line. These cells did have the advantage of being a widely used cell line, and they had an integrated NF$\kappa \mathrm{B}$ reporter. Finally, we do not provide data on a single overall mechanism of action of MSCs. Our studies to date $[33,35,51,52]$, and those of other groups $[15,53,54]$, indicate that the effects of MSCs on, for example, innate and adaptive immunity, including antimicrobial effects, are varied, context dependent and not encapsulated by a single secreted mediator or group of mediators. Nonetheless, we show that the mechanisms of MSC therapy via their secretome as a whole is enhanced with pre-activation and is partly mediated through KGF. 


\section{Conclusion}

In conclusion, we demonstrate that hMSCs cultured in xenogeneic material-free medium enhance the recovery and resolution of VILI when administered at clinically relevant time points following the establishment of injury. These xenogeneic hMSCs were similarly effective following cryopreservation and thawing to fresh MSCs. Cytokine pre-activation further enhanced the efficacy of cryopreserved xeno-free MSCs. KGF may mediate some of the protective effects of these cryopreserved xeno-free MSCs. Taken together, these findings address important translational concerns and significantly advances cryopreserved xeno-free hMSCs towards clinical testing for patients with ARDS.

\section{Supplementary information}

Supplementary information accompanies this paper at https://doi.org/10.1186/s40635-020-0295-5.

Additional file 1: Figure S1. hMSCs retain their secretary profile pre- and post-cryopreservation. IL-8 release by fresh naive hMSCs or fresh activated hMSCs is unaffected $24 \mathrm{~h}$ and $48 \mathrm{~h}$ post-thaw after cryopreservation. $n=3$ for all groups.

Additional file 2: Figure S2. Pre-activated, cryopreserved, XF-hMSCs enhance the resolution of alveolar cell counts. Fresh, but not cryopreserved, XF-hMSCs decreased alveolar cell counts, while cytokine pre-activation restored the efficacy of cryopreserved hMSCs in reducing alveolar cell counts. ${ }^{* *}$ and ${ }^{* * *} P<0.01$ and 0.001 , respectively, versus PBS control; ${ }^{\$} P<0.01$ versus naive cryopreserved group. Sham, $n=$; PBS control, $n=8$; fresh, $n=8$; fresh pre-activated, $n=7$; cryopreserved, $n=5$; cryopreserved pre-activated, $n=7$.

\section{Abbreviations}

ARDS: Acute respiratory distress syndrome; BAL: Bronchoalveolar lavage; BM-hMSCs: Bone marrow-derived hMSCs; CM: Conditioned medium; FBS: Foetal bovine serum; FGF: Fibroblast growth factor; hMSCs: Human mesenchymal stem/stromal cells; IFN: Interferon; IL: Interleukin; KGF: Keratinocyte growth factor; LDH: Lactate dehydrogenase; MEMa: Alpha Minimum Essential Eagle Medium; PBS: Phosphate-buffered saline; TNF: Tumour necrosis factor;

VILI: Ventilation-induced lung injury; XF: Xenogeneic-free

\section{Acknowledgements}

Not applicable

\section{Authors' contributions}

SH performed the experiments and assays, analysed the data, drafted the manuscript, and agreed to the final submitted version. DOT, MS and JL conceived and designed the experiments, analysed the data, drafted the manuscript and agreed to the final submitted version. SG, MM and FB reviewed the manuscript for content and agreed to the final submitted version.

\section{Funding}

This work was supported by funding from the Science Foundation Ireland (16/FRL/3845 to J. Laffey, 14/TIDA/2291 to D OToole), the European Research Council (ERC StG 207777 to J Laffey) and the Health Research Board Ireland (HRAPOR-2015-1099 to D O'Toole).

\section{Availability of data and materials}

All data generated or analysed during this study are included in this published article.

\section{Ethics approval and consent to participate}

All work was approved by the Animal Care in Research Ethics Committee of the National University of Ireland, Galway, and conducted under licence from the Health Products Regulatory Authority, Ireland. Specific pathogen-free adult male Sprague-Dawley rats (Charles River Laboratories, Kent, UK) weighing between 300 and $450 \mathrm{~g}$ were used in all experiments.

\section{Consent for publication}

Not applicable.

\section{Competing interests}

The patented xenogeneic-free (XF) culture supplement (WO2015121471 A1) was developed in the Regenerative Medicine Institute, National University of Ireland, Galway, Ireland.

\section{Author details}

${ }^{1}$ Anaesthesia, School of Medicine, National University of Ireland, Galway, Ireland. ${ }^{2}$ Regenerative Medicine Institute (REMEDI) at CÚRAM Centre for Research in Medical Devices, National University of Ireland Galway, Galway, Ireland. 
${ }^{3}$ Medicine, School of Medicine, National University of Ireland, Galway, Ireland. ${ }^{4}$ Department of Anaesthesia, Galway University Hospitals, Saolta University Health Group, Galway, Ireland.

Received: 16 November 2019 Accepted: 20 January 2020

Published online: 05 February 2020

\section{References}

1. Bellani G, Laffey JG, Pham T, Fan E, Brochard L, Esteban A, Gattinoni L, van Haren F, Larsson A, DF MA, Ranieri M, Rubenfeld G, Thompson BT, Wrigge H, Slutsky AS, Pesenti A, Investigators LS, Group ET (2016) Epidemiology, patterns of care, and mortality for patients with acute respiratory distress syndrome in intensive care units in 50 countries. JAMA 315:788-800

2. Rubenfeld GD, Caldwell E, Peabody E, Weaver J, Martin DP, Neff M, Stern EJ, Hudson LD (2005) Incidence and outcomes of acute lung injury. N Engl J Med 353:1685-1693

3. Hudson LD (1999) Progress in understanding ventilator-induced lung injury. JAMA 282:77-78

4. Mao M, Wang S, Lv X, Wang Y, Xu J (2010) Intravenous delivery of bone marrow-derived endothelial progenitor cells improves survival and attenuates lipopolysaccharide-induced lung injury in rats. Shock 34:196-204

5. Gupta N, Su X, Popov B, Lee J, Serikov V, Matthay M (2007) Intrapulmonary delivery of bone marrow-derived mesenchymal stem cells improves survival and attenuates endotoxin-induced acute lung injury in mice. J Immunol 179: 1855-1863

6. Ionescu L, Byrne R, van Haaften T, Vadivel A, Alphonse R, Rey-Parra G, Weissmann G, Hall A, Eaton F, Thébaud B (2012) Stem cell conditioned medium improves acute lung injury in mice: in vivo evidence for stem cell paracrine action. Am J Physiol Lung Cell Mol Physiol 303:L967-L977

7. Krasnodembskaya A, Samarani G, Song Y, Zhuo H, Su X, Lee J, Gupta N, Petrini M, Matthay M (2012) Human mesenchymal stem cells reduce mortality and bacteremia in gram-negative sepsis in mice in part by enhancing the phagocytic activity of blood monocytes. Am J Physiol Lung Cell Mol Physiol 302:L1003-L1013

8. Mei S, Haitsma J, Dos Santos C, Deng Y, Lai P, Slutsky A, Liles W, Stewart D (2010) Mesenchymal stem cells reduce inflammation while enhancing bacterial clearance and improving survival in sepsis. Am J Respir Crit Care Med 182 1047-1057

9. Nemeth K, Mayer B, Mezey E (2010) Modulation of bone marrow stromal cell functions in infectious diseases by toll-like receptor ligands. J Mol Med (Berlin) 88:5-10

10. Aguilar S, Scotton C, McNulty K, Nye E, Stamp G, Laurent G, Bonnet D, Janes S (2009) Bone marrow stem cells expressing keratinocyte growth factor via an inducible lentivirus protects against bleomycin-induced pulmonary fibrosis. PLoS One 4:e8013

11. Ortiz L, Gambelli F, McBride C, Gaupp D, Baddoo M, Kaminski N, Phinney D (2003) Mesenchymal stem cell engraftment in lung is enhanced in response to bleomycin exposure and ameliorates its fibrotic effects. Proc Natl Acad Sci U S A 100:8407-8411

12. Kotton D, Ma B, Cardoso W, Sanderson E, Summer R, Williams M, Fine A (2001) Bone marrow-derived cells as progenitors of lung alveolar epithelium. Development 128:5181-5188

13. Curley G, Hayes M, Ansari B, Shaw G, Ryan A, Barry F, O'Brien T, OToole D, Laffey J (2012) Mesenchymal stem cells enhance recovery and repair following ventilator-induced lung injury in the rat. Thorax 67:496-501

14. Curley G, Ansari B, Hayes M, Devaney J, Masterson C, Ryan A, Barry F, O'Brien T, Toole D, JG L (2013) Effects of intratracheal mesenchymal stromal cell therapy during recovery and resolution after ventilator-induced lung injury. Anesthesiology 118:924-932

15. Lee JW, Krasnodembskaya A, McKenna DH, Song Y, Abbott J, Matthay MA (2013) Therapeutic effects of human mesenchymal stem cells in ex vivo human lungs injured with live bacteria. Am J Respir Crit Care Med 187:751-760

16. Hayes M, Masterson C, Devaney J, Barry F, Elliman S, O'Brien T, OT D, Curley GF, Laffey JG (2015) Therapeutic efficacy of human mesenchymal stromal cells in the repair of established ventilator-induced lung injury in the rat. Anesthesiology 122:363-373

17. Wilson JG, Liu KD, Zhuo H, Caballero L, McMillan M, Fang X, Cosgrove K, Vojnik R, Calfee CS, Lee J, Rogers AJ, Levitt J, Wiener-Kronish J, Bajwa EK, Leavitt A, McKenna D, Thompson BT, Matthay MA (2014) Mesenchymal stem (stromal) cells for treatment of ARDS: a phase 1 clinical trial. Lancet Respir Med

18. Matthay MA, Calfee CS, Zhuo H, Thompson BT, Wilson JG, Levitt JE, Rogers AJ, Gotts JE, Wiener-Kronish JP, Bajwa EK, Donahoe MP, McVerry BJ, Ortiz LA, Exline M, Christman JW, Abbott J, Delucchi KL, Caballero L, McMillan M, McKenna DH, Liu KD (2018) Treatment with allogeneic mesenchymal stromal cells for moderate to severe acute respiratory distress syndrome (START study): a randomised phase 2a safety trial. Lancet Respir Med 7:154-162

19. François M, Copland IB, Yuan S, Romieu-Mourez R, Waller EK, Galipeau J (2012) Cryopreserved mesenchymal stromal cells display impaired immunosuppressive properties as a result of heat-shock response and impaired interferon- $\gamma$ licensing. Cytotherapy 14:147-152

20. Dimarakis I, Levicar N (2006) Cell culture medium composition and translational adult bone marrow-derived stem cell research. Stem Cells 24:1407-1408

21. Halme DG, Kessler DA (2006) FDA regulation of stem-cell-based therapies. N Engl J Med 355:1730-1735

22. Sundin M, Ringden O, Sundberg B, Nava S, Gotherstrom C, Le Blanc K (2007) No alloantibodies against mesenchymal stromal cells, but presence of anti-fetal calf serum antibodies, after transplantation in allogeneic hematopoietic stem cell recipients. Haematologica 92:1208-1215

23. Mackensen A, Drager R, Schlesier M, Mertelsmann R, Lindemann A (2000) Presence of IgE antibodies to bovine serum albumin in a patient developing anaphylaxis after vaccination with human peptide-pulsed dendritic cells. Cancer Immunol Immunother 49:152-156

24. Selvaggi TA, Walker RE, Fleisher TA (1997) Development of antibodies to fetal calf serum with arthus-like reactions in human immunodeficiency virus-infected patients given syngeneic lymphocyte infusions. Blood 89:776-779

25. Tuschong L, Soenen SL, Blaese RM, Candotti F, Muul LM (2002) Immune response to fetal calf serum by two adenosine deaminase-deficient patients after T cell gene therapy. Hum Gene Ther 13:1605-1610 
26. Barry FP, Mooney EJ, Murphy JM, Shaw GM, Gaynard SP (2015) Serum-free medium. In: editor (ed)^(eds) book serumfree medium. Google patents, City, pp.

27. Chen H, Min X-H, Wang Q-Y, Leung FW, Shi L, Zhou Y, Yu T, Wang C-M, An G, Sha W-H, Chen Q-K (2015) Pre-activation of mesenchymal stem cells with TNF- $\alpha$, LL-1 $\beta$ and nitric oxide enhances its paracrine effects on radiation-induced intestinal injury. Sci Rep 5:8718

28. Krampera M, Cosmi L, Angeli R, Pasini A, Liotta F, Andreini A, Santarlasci V, Mazzinghi B, Pizzolo G, Vinante F, Romagnani $P$, Maggi E, Romagnani S, Annunziato F (2006) Role for interferon-gamma in the immunomodulatory activity of human bone marrow mesenchymal stem cells. Stem Cells 24:386-398

29. Prasanna SJ, Gopalakrishnan D, Shankar SR, Vasandan AB (2010) Pro-inflammatory cytokines, IFNgamma and TNFalpha, influence immune properties of human bone marrow and Wharton jelly mesenchymal stem cells differentially. PLoS One 5:e9016

30. Wagner W, Wein F, Seckinger A, Frankhauser M, Wirkner U, Krause U, Blake J, Schwager C, Eckstein V, Ansorge W, Ho AD (2005) Comparative characteristics of mesenchymal stem cells from human bone marrow, adipose tissue, and umbilical cord blood. Exp Hematol 33:1402-1416

31. Horie S, Ansari B, Masterson C, Devaney J, Scully M, OToole D, Laffey JG (2016) Hypercapnic acidosis attenuates pulmonary epithelial stretch-induced injury via inhibition of the canonical NF-KB pathway. Intensive Care Med Exp 4:8

32. Morgan DML (1998) Tetrazolium (MTT) assay for cellular viability and activity. In: Morgan DML (ed) Polyamine protocols. Humana Press, Totowa, NJ, pp. 179-184

33. Curley GF, Ansari B, Hayes M, Devaney J, Masterson C, Ryan A, Barry F, O'Brien T, Toole DO, Laffey JG (2013) Effects of intratracheal mesenchymal stromal cell therapy during recovery and resolution after ventilator-induced lung injury. Anesthesiology 118:924-932

34. Curley GF, Contreras M, Higgins B, O'Kane C, McAuley DF, OToole D, Laffey JG (2011) Evolution of the inflammatory and fibroproliferative responses during resolution and repair following ventilator-induced lung injury in the rat. Anesthesiology 115:1022-1032

35. Curley GF, Hayes M, Ansari B, Shaw G, Ryan A, Barry F, O'Brien T, O'Toole D, Laffey JG (2012) Mesenchymal stem cells enhance recovery and repair following ventilator-induced lung injury in the rat. Thorax 67:496-501

36. Costello J, Higgins B, Contreras M, Chonghaile MN, Hassett P, O'Toole D, Laffey JG (2009) Hypercapnic acidosis attenuates shock and lung injury in early and prolonged systemic sepsis. Crit Care Med 37:2412-2420

37. Higgins BD, Costello J, Contreras M, Hassett P, O'Toole D, Laffey JG (2009) Differential effects of buffered hypercapnia versus hypercapnic acidosis on shock and lung injury induced by systemic sepsis. Anesthesiology 111:1317-1326

38. Laffey JG, Honan D, Hopkins N, Hyvelin JM, Boylan JF, McLoughlin P (2004) Hypercapnic acidosis attenuates endotoxininduced acute lung injury. Am J Respir Crit Care Med 169:46-56

39. Bolender RP, Hyde DM, Dehoff RT (1993) Lung morphometry: a new generation of tools and experiments for organ, tissue, cell, and molecular biology. Am J Phys 265:L521-L548

40. Moll G, Alm JJ, Davies LC, von Bahr L, Heldring N, Stenbeck-Funke L, Hamad OA, Hinsch R, Ignatowicz L, Locke M, Lönnies H, Lambris JD, Teramura Y, Nilsson-Ekdahl K, Nilsson B, Le Blanc K (2014) Do cryopreserved mesenchymal stromal cells display impaired immunomodulatory and therapeutic properties? Stem Cells (Dayton, Ohio) 32:2430-2442

41. Curley GF, Jerkic M, Dixon S, Hogan G, Masterson C, O'Toole D, Devaney J, Laffey JG (2016) Cryopreserved, xeno-free human umbilical cord mesenchymal stromal cells reduce lung injury severity and bacterial burden in rodent Escherichia coli-induced acute respiratory distress syndrome. Crit Care Med

42. Oikonomopoulos A, van Deen WK, Manansala A-R, Lacey PN, Tomakili TA, Ziman A, Hommes DW (2015) Optimization of human mesenchymal stem cell manufacturing: the effects of animal/xeno-free media. Sci Rep 5:16570

43. Aggarwal S, Pittenger MF (2005) Human mesenchymal stem cells modulate allogeneic immune cell responses. Blood 105:1815-1822

44. Bustos ML, Huleihel L, Meyer EM, Donnenberg AD, Donnenberg VS, Sciurba JD, Mroz L, McVerry BJ, Ellis BM, Kaminski N, Rojas M (2013) Activation of human mesenchymal stem cells impacts their therapeutic abilities in lung injury by increasing interleukin (IL)-10 and IL-1RN levels. Stem Cells Transl Med

45. Liu H, Lu K, MacAry PA, Wong KL, Heng A, Cao T, Kemeny DM (2008) Soluble molecules are key in maintaining the immunomodulatory activity of murine mesenchymal stromal cells. J Cell Sci 125:200-208

46. Hayes M, Curley GF, Masterson C, Devaney J, OToole D, Laffey JG (2015) Mesenchymal stromal cells are more effective than the MSC secretome in diminishing injury and enhancing recovery following ventilator-induced lung injury. Intensive Care Med Exp 3:1-14

47. de Witte SFH, Franquesa M, Baan CC, Hoogduijn MJ (2015) Toward development of iMesenchymal stem cells for immunomodulatory therapy. Front Immunol 6:648

48. Goolaerts A, Pellan-Randrianarison N, Larghero J, Vanneaux V, Uzunhan Y, Gille T, Dard N, Planes C, Matthay MA, Clerici C (2014) Conditioned media from mesenchymal stromal cells restore sodium transport and preserve epithelial permeability in an in vitro model of acute alveolar injury. Am J Physiol Lung Cell Mol Physiol 306: L975-L985

49. Jerkic M, Masterson C, Ormesher L, Gagnon S, Goyal S, Rabani R, Otulakowski G, Zhang H, Kavanagh BP, Laffey JG (2019) Overexpression of IL-10 enhances the efficacy of human umbilical-cord-derived mesenchymal stromal cells in E. coli pneumosepsis. J Clin Med, 8

50. Varkouhi AK, Jerkic M, Ormesher L, Gagnon S, Goyal S, Rabani R, Masterson C, Spring C, Chen PZ, Gu FX, Dos Santos CC, Curley GF, Laffey JG (2019) Extracellular vesicles from interferon-gamma-primed human umbilical cord mesenchymal stromal cells reduce Escherichia coli-induced acute lung injury in rats. Anesthesiology 130: 778-790

51. Devaney J, Horie S, Masterson C, Elliman S, Barry F, O'Brien T, Curley GF, O'Toole D, Laffey JG (2015) Human mesenchymal stromal cells decrease the severity of acute lung injury induced by $E$. coli in the rat. Thorax $70(7)$ : 625-635 
52. McAuley DF, Curley GF, Hamid UI, Laffey JG, Abbott J, McKenna DH, Fang X, Matthay MA, Lee JW (2014) Clinical grade allogeneic human mesenchymal stem cells restore alveolar fluid clearance in human lungs rejected for transplantation. Am J Physiol Lung Cell Mol Physiol 306:L809-L815

53. Fang X, Abbott J, Cheng L, Colby JK, Lee JW, Levy BD, Matthay MA (2015) Human mesenchymal stem (stromal) cells promote the resolution of acute lung injury in part through lipoxin A4. J Immunol 195:875-881

54. Monsel A, Zhu YG, Gennai S, Hao Q, Hu S, Rouby JJ, Rosenzwajg M, Matthay MA, Lee JW (2015) Therapeutic effects of human mesenchymal stem cell-derived microvesicles in severe pneumonia in mice. Am J Respir Crit Care Med 192:324-336

\section{Publisher's Note}

Springer Nature remains neutral with regard to jurisdictional claims in published maps and institutional affiliations.

Submit your manuscript to a SpringerOpen ${ }^{\circ}$ journal and benefit from:

- Convenient online submission

- Rigorous peer review

- Open access: articles freely available online

- High visibility within the field

- Retaining the copyright to your article

Submit your next manuscript at $\boldsymbol{\nabla}$ springeropen.com 